\title{
Factors associated with SARS-CoV-2 infection and outcome in patients with solid tumors or hematological malignancies: a single-center study
}

\author{
Anouk Goudsmit ${ }^{1} \cdot$ Edouard Cubilier $^{1} \cdot$ Anne-Pascale Meert $^{1} \cdot$ Philippe Aftimos $^{2} \cdot$ Konstantinos Stathopoulos $^{3}$. \\ Chloe Spilleboudt ${ }^{4}$. Angela Loizidou ${ }^{1}$ (i)
}

Received: 28 August 2020 / Accepted: 24 March 2021 / Published online: 14 April 2021

(C) The Author(s) 2021

\begin{abstract}
Background Immunocompromised cancer patients are presumed to be at high risk of developing COVID-19 infection. Predisposing factors to contracting COVID-19 and to severe outcomes have been described in registries but were not compared between solid tumors and hematological malignancies.

Method This retrospective single oncologic center study included adults with solid tumors or hematological malignancies referred to testing by naso-pharyngeal swab for a SARS-CoV-2 RT-PCR from March 10 to May 18, 2020.

Results A total of 212 patients were included in the study. Forty-five (21\%) were tested positive with SARS-CoV-2. The univariate analysis with positive SARS-CoV-2 PCR as a dependent variable reveals significant odds ratios (ORs) for agewith a mean of 62.5 years - (OR: $1.05,95 \%$ CI: 1.02-1.08), performance status $\geq 2$ (OR: 2.38, 95\% CI: 1.22-4.70), inpatient status (OR: 2.36, 95\% CI: 1.11-4.91), and hematological malignancies (OR: 2.48, 95\% CI: 1.23-4.96). In contrast, OR for solid tumors reveals a negative association (OR: $0.40,95 \%$ CI: $0.20-0.81$ ). When integrating severe outcome (ICU admission or COVID-19-related death) as a dependent variable, the univariate logistic regression model shows significant ORs for pre-existing lymphopenia (OR: 4.0, 95\% CI: 1.17-15.04), hematological malignancies (OR: 3.73, 95\% CI: 1.09-13.80), and a negative association for solid tumors (OR: 0.27; 95\% CI: 0.07-0.92).

Conclusion In patients referred for SARS-CoV-2 testing, hematological malignancies were associated with a higher risk of COVID-19 infection and severe outcomes. Other factors were age and inpatient status.
\end{abstract}

Keywords SARS-CoV-2 $\cdot$ COVID-19 $\cdot$ Solid tumor $\cdot$ Hematological malignancies

Anouk Goudsmit, Edouard Cubilier, Chloe Spilleboudt and Angela Loizidou contributed equally to this work.

Anouk Goudsmit

anouk.goudsmit@bordet.be

Edouard Cubilier

edouard.cubilier@bordet.be

Anne-Pascale Meert

ap.meert@bordet.be

Philippe Aftimos

philippe.aftimos@bordet.be

Konstantinos Stathopoulos

konstantinos.stathopoulos@bordet.be

Chloe Spilleboudt

Chloe.Spilleboudt@bordet.be
Angela Loizidou

angela.loizidou@bordet.be

1 Internal Medicine, Institut Jules Bordet, rue Heger 1, 1000 Brussels, Belgium

2 Clinical Trials Conduct Unit, Institut Jules Bordet, rue Heger 1, 1000 Brussels, Belgium

3 Imaging Department, Institut Jules Bordet, rue Heger 1, 1000 Brussels, Belgium

4 Hematology Department, Institut Jules Bordet, rue Heger 1, 1000 Brussels, Belgium 


\section{Introduction}

A novel coronavirus, named severe acute respiratory syndrome coronavirus 2 (SARS-CoV-2), was identified in China in December 2019 and caused a pandemic in a few weeks mostly by human-to-human transmission [1]. The infectious disease related to SARS-CoV-2 (COVID-19) produces various symptoms scaling from asymptomatic, to mild such as cough and fever, to severe such as acute respiratory distress syndrome (ARDS) and multiple organ failure (MOF) [2].

In the first studies, the diagnosis of COVID-19 was established by epidemiological and clinical suspicion, followed by thoracic computed tomography scanner (CT scan) in which the pattern evolves during the course of infection, starting with unilateral ground-glass opacification, to consolidation and bronchiectasis, to thickening of adjacent pleura and pleural effusion after 3 weeks, with a tendency to develop from a unilateral involvement at first, to a bilateral and multifocal form after a few days [3]. Genomic characterization of this new coronavirus [4] then allowed Corman et al. to develop the first real-time reverse transcription polymerized chain reaction (RT-PCR) for SARS-CoV-2 detection, to precise the diagnosis of COVID-19 [5], which has been used as diagnosis criteria in the more recent studies.

In cancer patients, community respiratory viruses are an important cause of respiratory infections [6], and adverse outcomes occur more frequently in comparison to immunocompetent patients [7]. In China, the prevalence of cancer in patients with COVID-19 was $2.0 \%$ which is higher than the overall cancer incidence of $0.29 \%$ [8]. Mortality rate in these patients is also increased in comparison with non-cancer patients $[9,10]$.

In the general population, risk factors for a more severe outcome of COVID-19 infection are older age, higher SOFA score, D-dimer $>1 \mu \mathrm{g} / \mathrm{mL}$ at admission [11], and comorbidities [12].

Previous reports concerning cancer patients and COVID19 highlighted the following predisposing factors for severe complications (ICU admission and death): Eastern Cooperative Oncology Group Performance Status (ECOG PS) $\geq 2$ and progressive malignant disease [13], metastatic cancer patients [14], anti-cancer treatment administered within 14 days [15], hematological malignancies in comparison to health care providers with COVID-19 [16], and patients with solid tumors [17].

Our study aims to compare the factors associated with a SARS-CoV-2 infection and its outcomes among patients with solid tumors or hematological malignancies, as highlighted in a previously published study, but with the population of a tertiary oncological center in Brussels.

\section{Methods}

\section{Study design}

This study included all patients with hematological malignancies or solid tumors followed at Institute Jules Bordet who were referred for a nasopharyngeal swab between March 10, 2020, and May 18, 2020, during COVID-19 pandemic. Nasopharyngeal swabs were analyzed with the Altona RealStar ${ }^{\circledR}$ reverse transcriptase PCR SARS-CoV-2. Referral criteria were as follows: symptoms of COVID-19 (fever, cough, shortness of breath, desaturation, sore throat, rhinorrhea, headache, nausea, or diarrhea), a close contact with a confirmed case or incidental imaging findings compatible with COVID19 infection (ground-glass opacity or crazy paving pattern). Patients with strong clinical or imaging signs of COVID-19 were tested twice if the first test was negative (by nasopharyngeal swab or BAL). Onset time of the infection was based on the beginning of symptoms, or in asymptomatic patients the day of the naso-pharyngeal swab.

The study was approved by the Ethics Committee of the Institut Jules Bordet on May 26, 2020.

\section{Data collection}

Collected data included demographics, symptoms, comorbidities, performance status, type and stage of cancer, anticancer treatment (chemotherapy, immunotherapy, or targeted therapy), blood work-up, CT scan, and severe outcome as defined by admission to the intensive care unit (ICU) or death attributed to COVID-19. Chronic steroid use was defined by a daily dose over $20 \mathrm{mg}$ of prednisone per day with a cumulative dose over $700 \mathrm{mg}$ [18].

\section{Outcome}

The primary endpoint was the incidence of COVID-19 among patients with concordant symptoms, close contact with a confirmed case or concordant imaging. The secondary outcome was the occurrence of a severe outcome, consisting of an admission to the Intensive Care Unit (ICU) or death attributed to COVID-19 among positive patients.

\section{Statistical analyses}

We used descriptive statistics to show the baseline demographic information of the included patients. A series of statistical tests were made for two different dependent variables, the positive SARS-CoV-2 RT-PCR and the severe outcome. The association between dependent variables and explicative variables was assessed by a chi-squared test with a threshold of significance defined by $p<0.05$, followed by a univariate analysis calibrated with $95 \%$ CIs $(p$-value < 0.05 ) for ORs. Finally, multivariate 
logistic analyses were carried out on significant variables at a $5 \%$ level in the univariate analysis.

\section{Results}

\section{Characteristics of the included patients}

A total of 212 patients were tested by RT-PCR for SARS-CoV2: 163 for symptoms of COVID-19 (77\%), 29 for incidental imaging findings compatible with COVID-19 (14\%), and 20 for contact with a confirmed case $(9 \%)$. Demographic, clinical, and tumor characteristics are described in Table 1. Mean age was 64 years with $55 \%$ female. Thirty-two $(15.2 \%)$ were active smokers and $78(37.0 \%)$ had a smoking history. A total of 155 $(73 \%)$ patients had solid tumors and 57 (27\%) hematological malignancies. The predominant anti-cancer treatment received was chemotherapy and concerned $94(44.3 \%)$ patients, 82
(45.6\%) had received anti-cancer treatments within 14 days, and $44(24.4 \%)$ between 14 and 30 days from PCR-test day. Ninety-seven $(46 \%)$ had a chronic lymphopenia $\left(<1000 / \mathrm{mm}^{3}\right)$ and $17(8 \%)$ were on chronic steroid medication. Eighty-seven $(41.0 \%)$ had a bad performance status of 2 or more and 44 $(20.9 \%)$ were already hospitalized. Severity of lung damage is assessed with a score from 1 to 4 according to the classification of the Thoracic Imaging Society of the French Society of Radiology (http://www.sfrnet.org/rc/org/sfrnet/nws/News/2020/ 20200316-155630-175/src/nws fullText/fr/CR TYPE COVID19 LAST.pdf). A total of $169(80 \%)$ chest CT-scans were performed with a global median pulmonary grade of 1 (Table 2).

\section{Characteristics and statistical analysis for positive SARS-CoV-2 PCR patients}

Forty-five (21\%) SARS-CoV-2 PCR were found to be positive: 33 among patients tested for symptoms of COVID-19 (20\%), 3
Table 1 Characteristics of cancer patients with positive PCR SARS-CoV-2 Univariate analysis

\begin{tabular}{|c|c|c|c|c|}
\hline$N=45(21 \%)$ & Ratio & OR & IC & $\begin{array}{l}p \text { - } \\
\text { value }\end{array}$ \\
\hline Age, median (years) & 70 & 1.05 & $1.02-1.08$ & 0.001 \\
\hline $\operatorname{Sex}, \operatorname{men}(n, \%)$ & $23(51 \%)$ & 1.38 & $0.71-2.68$ & 0.339 \\
\hline Solid cancer $(n, \%)$ & $26(58 \%)$ & 0.40 & $0.20-0.81$ & 0.01 \\
\hline Metastatic disease $(n, \%)$ & $20(77 \%)$ & 2.48 & $0.98-7.15$ & 0.069 \\
\hline Hematological malignancies $(n, \%)$ & $19(42 \%)$ & 2.48 & $1.23-4.96$ & 0.01 \\
\hline Remission & $7(15 \%)$ & 2.38 & $0.84-6.34$ & 0.088 \\
\hline Hypertension $(n, \%)$ & $22(49 \%)$ & 1.43 & $0.73-2.77$ & 0.291 \\
\hline Dyslipidemia $(n, \%)$ & $12(27 \%)$ & 1.42 & $0.65-2.99$ & 0.364 \\
\hline Diabetes $(n, \%)$ & $8(18 \%)$ & 1.17 & $0.46-2.71$ & 0.720 \\
\hline Stroke $(n, \%)$ & $3(7 \%)$ & 1.01 & $0.22-3.42$ & 0.985 \\
\hline Thromboembolic disease $(n, \%)$ & $3(7 \%)$ & 0.72 & $0.16-2.32$ & 0.622 \\
\hline $\operatorname{COPD}(n, \%)$ & $2(4 \%)$ & 0.32 & $0.05-1.16$ & 0.137 \\
\hline Active smoker $(n, \%)$ & $5(11 \%)$ & 0.64 & $0.21-1.65$ & 0.396 \\
\hline Ex-smoker $(n, \%)$ & $18(40 \%)$ & 1.18 & $0.59-2.30$ & 0.635 \\
\hline BMI, mean $\mathrm{kg} / \mathrm{m}^{2}$ & 25.7 & 1.03 & $0.96-1.10$ & 0.433 \\
\hline Performance status $>2$ & $15(33 \%)$ & 2.38 & $1.22-4.70$ & 0.011 \\
\hline Inpatient $(n, \%)$ & $15(33 \%)$ & 2.36 & $1.11-4.91$ & 0.022 \\
\hline Chronic lymphopenia (n, \%) & $21(47 \%)$ & 0.98 & $0.50-1.89$ & 0.946 \\
\hline Aplasia $(n, \%)$ & $3(7 \%)$ & 2.30 & $0.46-9.76$ & 0.267 \\
\hline Chemotherapy $(n, \%)$ & $15(33 \%)$ & 0.56 & $0.27-1.10$ & 0.097 \\
\hline Immunotherapy $(n, \%)$ & $2(4 \%)$ & 0.39 & $0.06-1.41$ & 0.212 \\
\hline Targeted therapy $(n, \%)$ & $8(18 \%)$ & 0.91 & $0.37-2.07$ & 0.833 \\
\hline Last treatment within 14 days $(n, \%)$ & $17(38 \%)$ & 0.81 & $0.39-1.62$ & 0.55 \\
\hline Last treatment from 14 to 30 days $(n, \%)$ & $6(13 \%)$ & 0.46 & $0.16-1.10$ & 0.102 \\
\hline Chronic steroid medication $(n, \%)$ & $5(11 \%)$ & 1.61 & $0.49-4.63$ & 0.393 \\
\hline $\mathrm{CT}$ chest $(n, \%)$ & $38(84 \%)$ & & & \\
\hline Radiologic grade (SFR), median & 2 & & & \\
\hline
\end{tabular}


Table 2 Univariate analysis for severe outcome of patients with cancer and positive PCR SARS $\mathrm{CoV}-2$

\begin{tabular}{|c|c|c|c|c|}
\hline$N=18(36 \%)$ & Ratio & OR & IC & $\begin{array}{l}p \text { - } \\
\text { value }\end{array}$ \\
\hline Age, median (years) & 72 & 1.02 & $0.96-1.10$ & 0.514 \\
\hline $\operatorname{Sex}, \operatorname{men}(n, \%)$ & $10(55 \%)$ & 1.35 & $0.41-4.56$ & 0.627 \\
\hline Solid cancer $(n, \%)$ & $7(39 \%)$ & 0.27 & $0.07-0.92$ & 0.04 \\
\hline Metastatic disease $(n, \%)$ & $6(33 \%)$ & 2.14 & $0.26-45.74$ & 0.525 \\
\hline Hematological malignancies $(n, \%)$ & $11(61 \%)$ & 3.73 & $1.09-13.80$ & 0.04 \\
\hline Remission & $4(22 \%)$ & 2.29 & $0.44-13.07$ & 0.322 \\
\hline Hypertension $(n, \%)$ & $9(50 \%)$ & 1.08 & $0.32-3.59$ & 0.903 \\
\hline Dyslipidemia $(n, \%)$ & $5(28 \%)$ & 1.10 & $0.27-4.20$ & 0.891 \\
\hline Diabetes $(n, \%)$ & $4(22 \%)$ & 1.64 & $0.34-8.00$ & 0.527 \\
\hline Stroke $(n, \%)$ & $1(5 \%)$ & 0.74 & $0.03-8.27$ & 0.808 \\
\hline Thromboembolic disease $(n, \%)$ & $1(5 \%)$ & 0.74 & $0.03-8.27$ & 0.808 \\
\hline $\operatorname{COPD}(n, \%)$ & 0 & & & \\
\hline Active smoker $(n, \%)$ & $1(5 \%)$ & 0.34 & $0.02-2.55$ & 0.351 \\
\hline $\operatorname{Ex}$-smoker $(n, \%)$ & $9(50 \%)$ & 2.00 & $0.59-6.97$ & 0.266 \\
\hline BMI, mean $\mathrm{kg} / \mathrm{m}^{2}$ & 26.4 & 1.06 & $0.92-1.25$ & 0.435 \\
\hline Performance status $>2$ & 2 & 1.26 & $0.38-4.36$ & 0.712 \\
\hline Inpatient $(n, \%)$ & $7(39 \%)$ & 1.51 & $0.42-5.39$ & 0.520 \\
\hline Chronic lymphopenia $(n, \%)$ & $12(67 \%)$ & 4.00 & $1.17-15.04$ & 0.032 \\
\hline Aplasia $(n, \%)$ & $1(5 \%)$ & 0.74 & $0.03-8.27$ & 0.808 \\
\hline Chemotherapy $(n, \%)$ & $7(39 \%)$ & 1.51 & $0.42-5.39$ & 0.520 \\
\hline Immunotherapy $(n, \%)$ & $1(5 \%)$ & 1.53 & $0.06-40.45$ & 0.769 \\
\hline Targeted therapy $(n, \%)$ & $5(28 \%)$ & 3.08 & $0.65-17.02$ & 0.164 \\
\hline Last treatment within 14 days $(n, \%)$ & $7(39 \%)$ & 0.98 & $0.27-3.47$ & 0.975 \\
\hline Last treatment from 14 to 30 days $(n, \%)$ & $4(22 \%)$ & 3.38 & $0.58-26.96$ & 0.192 \\
\hline Chronic steroid medication $(n, \%)$ & $3(17 \%)$ & 2.50 & $0.37-20.68$ & 0.345 \\
\hline $\mathrm{CT}$ chest $(n, \%)$ & $16(89 \%)$ & & & \\
\hline Radiologic grade (SFR), median & 3 & & & \\
\hline
\end{tabular}

for incidental imaging findings compatible with COVID-19 (10\%), and 9 for contact with a confirmed case $(45 \%)$. Demographic, clinical, and oncologic characteristics of this sub-group are described in Table 1 . We found a mean age of 70 years in the positive and 62 years in the negative group. We included $51 \%$ of men in the whole population but we found a reverse sex ratio in the positive SARS-CoV-2 PCR group with $45 \%$ of men. The mean BMI was 25.7 in the positive group and 24.8 in the negative group. Distribution between solid and hematological malignancies in the positive group was reversed from the distribution in the whole population with $58 \%$ of solid tumor patients versus $42 \%$ of hematological patients (Table 3 ). The median performance status was 1 in the negative-PCR SARS-CoV-2 group and 2 in the positive group. Thirty-three percent were inpatients. Further examinations are described in Table 1 . The median radiologic grade in positive tested patients was 2 versus 1 in negative patients, and $89 \%$ of patients who had a severe outcome presented a high median pulmonary grade of 3 , compared to a median grade of 1 for the positive lab-test group with a non-severe outcome.
A statistical analysis considering a positive SARS-CoV-2 RT-PCR as a dependent variable was performed. Chi-squared test results reveal significant association with age $(p=0.001)$, ECOG performance status $\geq 2(p=0.016)$, solid tumors $(p=0.013)$, hematological malignancies $(p=0.013)$, and inpatients $(p=0.037)$. A univariate analysis shows significant positive ORs for a mean age of 62.5 years (OR: $1.05,95 \% \mathrm{CI}$ : 1.02-1.08), a ECOG PS $\geq 2$ (OR: 2.38, 95\% CI: 1.22-4.70), hematological malignancies (OR: 2.48, 95\% CI: 1.23-4.96), and inpatients (OR: 2.36, 95\% CI: 1.11-4.91). On the other hand, association between positive SARS-CoV-2 PCR and solid tumors appears negative (OR: $0.40,95 \%$ CI: 0.20 0.81 ). The correspondent results are displayed in Table 1 and Fig. 1.

\section{Characteristics and statistical analysis for patients with severe outcome}

Sixteen patients with positive SARS-CoV-2 PCR had severe outcome; 9 patients were admitted in the ICU and 7 died from 

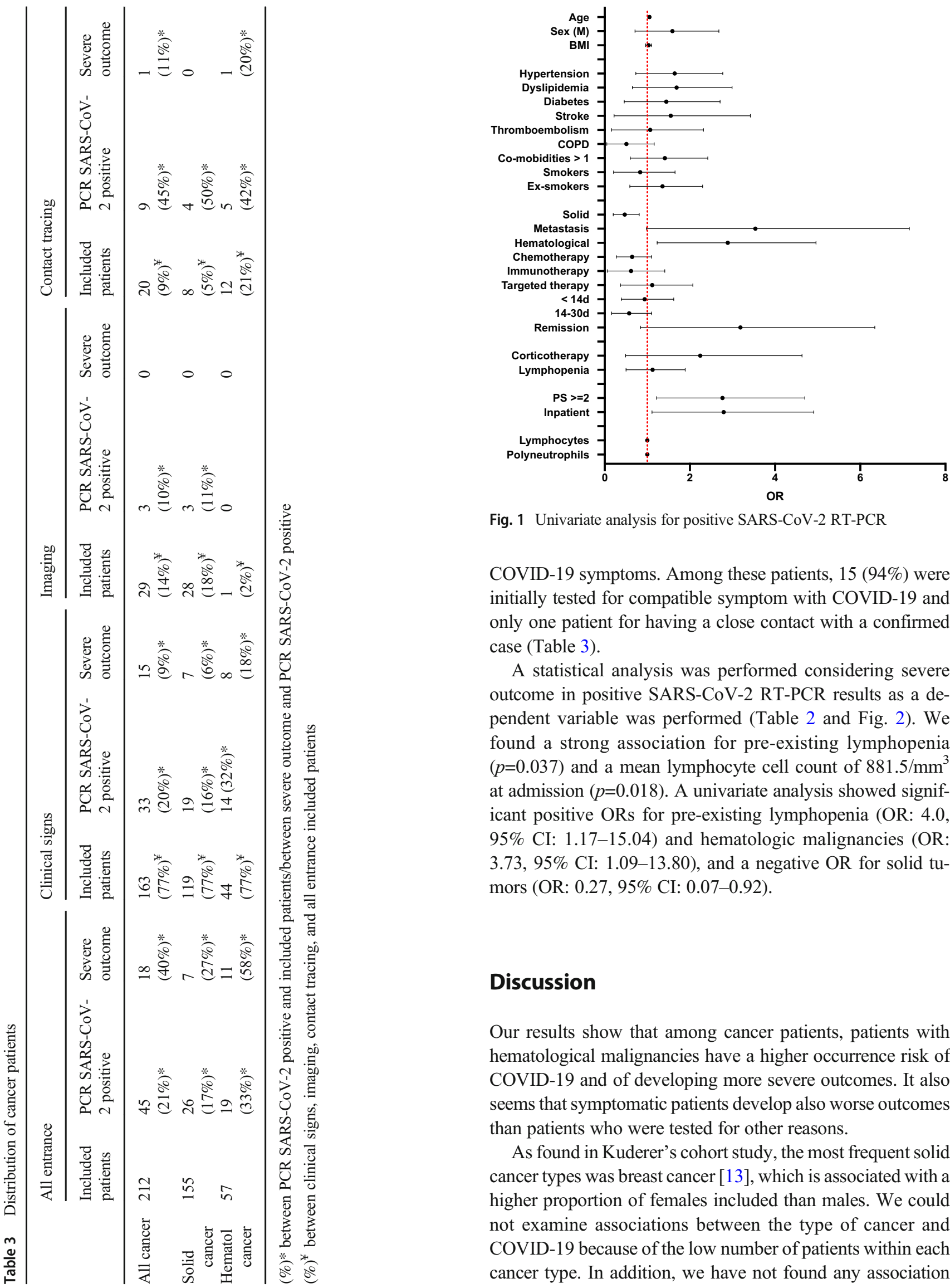

Fig. 1 Univariate analysis for positive SARS-CoV-2 RT-PCR

COVID-19 symptoms. Among these patients, 15 (94\%) were initially tested for compatible symptom with COVID-19 and only one patient for having a close contact with a confirmed case (Table 3).

A statistical analysis was performed considering severe outcome in positive SARS-CoV-2 RT-PCR results as a dependent variable was performed (Table 2 and Fig. 2). We found a strong association for pre-existing lymphopenia $(p=0.037)$ and a mean lymphocyte cell count of $881.5 / \mathrm{mm}^{3}$ at admission $(p=0.018)$. A univariate analysis showed significant positive ORs for pre-existing lymphopenia (OR: 4.0, 95\% CI: 1.17-15.04) and hematologic malignancies (OR: 3.73, 95\% CI: $1.09-13.80$ ), and a negative OR for solid tumors (OR: 0.27, 95\% CI: 0.07-0.92).

\section{Discussion}

Our results show that among cancer patients, patients with hematological malignancies have a higher occurrence risk of COVID-19 and of developing more severe outcomes. It also seems that symptomatic patients develop also worse outcomes than patients who were tested for other reasons.

As found in Kuderer's cohort study, the most frequent solid cancer types was breast cancer [13], which is associated with a higher proportion of females included than males. We could not examine associations between the type of cancer and COVID-19 because of the low number of patients within each cancer type. In addition, we have not found any association 
Fig. 2 Univariate analysis for severe outcome

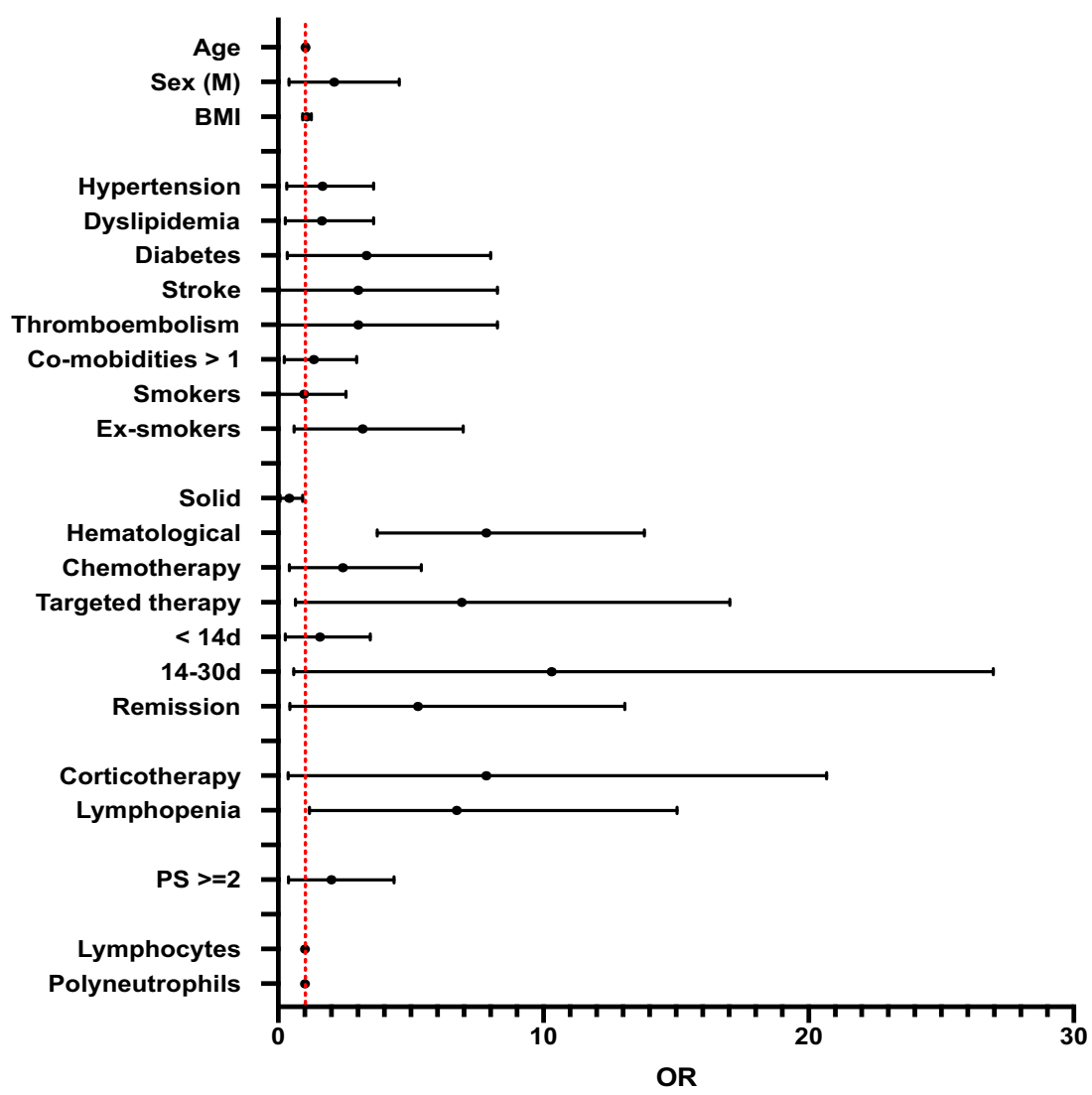

between pulmonary metastasis and positive RT-PCR SARSCoV-2 or severe outcome unlike in other studies [14].

We obtained an association with age coming out as a $5 \%$ risk increase to have a positive RT-PCR SARS-CoV-2 every each year, which correlates with results found in other publications [13].

Concerning medical history, we did not find any association between six chosen co-morbidities (hypertension, dyslipidemia, diabetes, thromboembolic disease, chronic obstructive pulmonary disease COPD) and a positive RT-PCR SARSCoV-2 test or a severe outcome. This observation extends to cardiovascular co-morbidities, which, although being the most frequent co-morbidities in other studies that include non-cancer patients, had not shown significant statistical association with our dependent variables. This observation contradicts results found in other studies that included non-cancer patients [19] but mirrors those including cancer patients [9, 17]. This could be explained by the important impact of cancer itself on the studied variables.

We used the ECOG PS to split patients in two groups between good ( $\mathrm{PS}<2$ ) and poor ( $\mathrm{PS} \geq 2$ ) performance status. We found an association between the RT-PCR SARS-CoV-2 results and a bad PS in univariate logistic regression but also if the patient was hospitalized at the time of the swab, although these two co-variables are closely associated because patients are more hospitalized when their general condition is poor, and long hospitalizations tend to induce a lower PS. These results are similar to those recently published in the CCC19 cohort [13].

In contrary to other studies, we have not found any association between recent treatment, such as chemotherapy, targeted therapy, or immunotherapy, and COVID-19 or severe outcome. These results can be explained by a rapid application of oncology guidelines during COVID-19 pandemic (NICE, ESMO, EBMT...) which limited delivery of systemic anti-cancer treatments for stable cancer patients with COVID-19 (https://www. esmo.org/guidelines/cancer-patient-management-during-thecovid-19-pandemic. https://www.nice.org.uk/). It has been established that there can be a potential overlap between the coronavirus-related interstitial pneumonia and the possible pneumological toxicity of anti-PDL1 agents [20], but too few patients were included in this study to test this hypothesis. In the matter of treatments, we have not found any association between COVID-19 and chronic steroid use, which has not been highlighted in any other study either, despite known increased risk of infections in patients under such therapy at a cumulative level of $700 \mathrm{mg}$ of prednisone [18].

At the beginning of the pandemic, there was limited available stock of personal protective equipment (PPE) and no PCR SARS-CoV-2 swab surveillance on admission day for 
hospitalized patients. We observed four nosocomial infections, one in the hematology unit, one in the palliative care unit, one in the oncology unit, and one in our surgical ICU. Moreover, $45 \%$ of patients who had contact with a confirmed case had a positive SARS-CoV-2 PCR (in comparison to $20 \%$ of positive PCR among patients with compatible symptoms and $10 \%$ among patients with compatible imaging). Thereafter, surveillance by nasopharyngeal swab was set up for every hospitalized patient and care-provider with at least one symptom suggestive of a COVID-19 nosocomial infection. It is important to note that two patients with a COVID-19 infection were in process of allogenic stem cell transplantation, one needed ICU care, and none of them died.

About the indication of having a nasopharyngeal swab test for COVID-19, 163 patients were tested for symptoms of COVID-19 (77\%), 29 for incidental imaging findings compatible with COVID-19 (14\%), and 20 for contact with a confirmed case (9\%). During the same period, 426 patients visited the Emergency Department for all kind of reason, 627 patients were hospitalized (and so, at higher risk for having a contact with infected medical staff), and 1511 patients underwent a thoracic CT scan (including PET-CT). Among patients with positive RT-PCR for SARS-CoV-2, 45\% of patients were initially tested for having a close contact with a confirmed case, in comparison to $20 \%$ of patients with compatible symptoms and $10 \%$ of patients with compatible imaging with COVID-19. However, $94 \%$ of patients with a severe outcome were initially tested because of compatible symptoms with COVID-19 and more precisely with respiratory symptoms (cough and desaturation) and/or fever. Among the 16 patients with a severe outcome, 7 were known for having a solid tumor (37\% of solid tumor patients with a positive SARS-CoV-2 PCR) and 8 with a hematological malignancy ( $57 \%$ of hematological patients with a positive SARS-CoV-2 PCR).

About the correlation between CT scan and RT-PCR, a total of 197/212 patients underwent RT-PCR test and chest CT scan. 61/197 (31\%) had negative RT-PCR test and negative CT findings. 72/197 (37\%) had negative RT-PCR test and atypical CT findings for COVID-19 pneumonia. 46/197 (23\%) presented positive RT-PCR test and positive CT findings for COVID-19. Nevertheless, our data does not allow to establish a statistical correlation between the positivity of the CT scan and the positivity of the RT-PCR. This question is explored, in the same population, in another study [21].

We highlighted an association with pre-existing lymphopenia and hematological malignancies, which are linked variables since in our population, $40 \%$ of patients with solid tumors had pre-existing lymphopenia against $60 \%$ in the hematological population.

When studying mortality by the severe outcome variable, we defined death related to COVID-19 by separating patients who presented worsening symptoms of COVID-19 (22\%), from death not related to COVID-19 when from complications associated with their cancer (13\%). In fact, with the nosocomial infection in our supportive care ward, and considering the difficulties of organizing outer hospital palliative care treatments for positive COVID-19 patients for sanitary reasons, end of life care occurred in the COVID-19 unit. Moreover, $93 \%$ of deceased patients, either positive or not for COVID-19, had active limitations of care.

The study has several limitations. First, it is a retrospective, single-center study. Second, the study took place during the first 3 months of the COVID-19 pandemic; as a consequence, we did not collect or analyze information about the clinical evolution of the patients, rehabilitation, and the post-COVID 19 syndrome beyond this limited study period. Another limitation is that, in the beginning of the pandemic, there was a lack of reagent for RT-PCR, so the nasopharyngeal swab was reserved only for patients with high suspicion of COVID-19 infection and undergoing anti-cancer therapy.

In conclusion, we confirm that among cancer patients, hematological malignancies have a higher occurrence risk of COVID-19 and develop more severe outcomes and that hygiene precautions must be introduced as soon as possible during a pandemic.

Further studies designed to explore the difference between solid and hematological patients with bigger sample sizes are needed to complete the available data on the impact of the intrinsic immunocompromised state and the immunosuppressive treatments on the seroprevalence, the seroconversion, the possibility of reinfection, the immunological protection after vaccination, and the survival after SARS-CoV-2 exposure.

Abbreviations SARS-CoV-2, severe acute respiratory syndrome coro-
navirus 2; COVID-19, coronavirus infectious disease; RT-PCR, reverse
transcription polymerized chain reaction; OR, odds ratio; 95\% CI, confi-
dence interval at 95\%; ARDS, acute respiratory distress syndrome; MOF,
multiple organ failure; ECOG, Eastern Cooperative Oncology Group; PS,
performance status; CT scan, computed tomography scan; ICU, intensive
care unit; BMI, body mass index; COPD, chronic obstructive pulmonary
disease; NICE, National Institute of Health and Care Excellence; PPE,
personal protective equipment Code availability N/A

Author contribution Dr Goudsmit conceptualized and designed the study, drafted the manuscript, collected data, and reviewed and revised the manuscript. Dr Cubilier conceptualized and designed the study, collected data, and reviewed and revised the manuscript. Dr Meert conceptualized and designed the study, and reviewed and revised the manuscript. Dr Aftimos conceptualized and designed the study, and reviewed and revised the manuscript. Dr Stathopoulos analyzed and collected imaging data. Dr Spilleboudt conceptualized and designed the study, collected data, and reviewed and revised the manuscript. Dr Loizidou conceptualized and designed the study, and reviewed and revised the manuscript.

Funding No external funding was needed to realize this study.

Data availability Data are extracted from the medical files of studied patients, after approval of the Ethical Committee of Institut Jules Bordet. 


\section{Declarations}

Ethics approval Approval of the Ethics Committee of Institut Jules Bordet the 26th of May 2020.

\section{Consent to participate N/A (retrospective study)}

Consent for publication N/A (retrospective study)

Conflict of interest All the authors do not have any conflict of interest and there was no funding for the study. We have full control of all primary data and we agree to allow the journal to review their data if requested.

Open Access This article is licensed under a Creative Commons Attribution 4.0 International License, which permits use, sharing, adaptation, distribution and reproduction in any medium or format, as long as you give appropriate credit to the original author(s) and the source, provide a link to the Creative Commons licence, and indicate if changes were made. The images or other third party material in this article are included in the article's Creative Commons licence, unless indicated otherwise in a credit line to the material. If material is not included in the article's Creative Commons licence and your intended use is not permitted by statutory regulation or exceeds the permitted use, you will need to obtain permission directly from the copyright holder. To view a copy of this licence, visit http://creativecommons.org/licenses/by/4.0/.

\section{References}

1. Chan JF-W, Yuan S, Kok K-H, To KK-W, Chu H, Yang J et al (2020) A familial cluster of pneumonia associated with the 2019 novel coronavirus indicating person-to-person transmission: a study of a family cluster. Lancet. 395(10223):514-523

2. Chen N, Zhou M, Dong X, Qu J, Gong F, Han Y, Qiu Y, Wang J, Liu Y, Wei Y, Xia J', Yu T, Zhang X, Zhang L (2020) Epidemiological and clinical characteristics of 99 cases of 2019 novel coronavirus pneumonia in Wuhan, China: a descriptive study. Lancet. 395(10223):507-513

3. Shi H, Han X, Jiang N, Cao Y, Alwalid O, Gu J, Fan Y, Zheng C (2020) Radiological findings from 81 patients with COVID-19 pneumonia in Wuhan, China: a descriptive study. Lancet Infect Dis 20(4):425-434

4. Lu R, Zhao X, Li J, Niu P, Yang B, Wu H et al (2020) Genomic characterisation and epidemiology of 2019 novel coronavirus: implications for virus origins and receptor binding. Lancet. 395(10224):565-574

5. Corman VM, Landt O, Kaiser M, Molenkamp R, Meijer A, Chu DKW, Bleicker T, Brünink S, Schneider J, Schmidt ML, Mulders DG, Haagmans BL, van der Veer B, van den Brink S, Wijsman L, Goderski G, Romette J-L, Ellis J, Zambon M, Peiris M, Goossens H, Reusken C, Koopmans MP, Drosten C (2020) Detection of 2019 novel coronavirus (2019-nCoV) by real-time RT-PCR. Euro Surveill 25(3):pii=2000045. https://doi.org/10.2807/1560-7917. ES.2020.25.3.2000045

6. Whimbey E, Englund JA, Couch RB (1997) Community Respiratory Virus Infections in Immunocompromised patients with cancer. Am J Med 102(3):10-18

7. Hijano DR, Maron G, Hayden RT (2018) Respiratory viral infections in patients with cancer or undergoing hematopoietic cell transplant. Front Microbiol 9:3097

8. Desai A, Sachdeva S, Parekh T, Desai R (2020) COVID-19 and cancer: lessons from a pooled meta-analysis. JCO Glob Oncol 6: $557-559$
9. Meng Y, Lu W, Guo E, Liu J, Yang B, Wu P et al (2020) Cancer history is an independent risk factor for mortality in hospitalized COVID-19 patients: a propensity score-matched analysis. J Hematol Oncol 13(1):75

10. Giannakoulis VG, Papoutsi E, Siempos II (2020) Effect of cancer on clinical outcomes of patients with COVID-19: a meta-analysis of patient data. JCO Glob Oncol. 6:799-808

11. Zhou F, Yu T, Du R, Fan G, Liu Y, Liu Z et al (2020) Clinical course and risk factors for mortality of adult inpatients with COVID-19 in Wuhan, China: a retrospective cohort study. Lancet. 395(10229):1054-1062

12. Du R-H, Liang L-R, Yang C-Q, Wang W, Cao T-Z, Li M et al (2020) Predictors of mortality for patients with COVID-19 pneumonia caused by SARS-CoV-2: a prospective cohort study. Eur Respir J 55(5):2000524

13. Kuderer NM, Choueiri TK, Shah DP, Shyr Y, Rubinstein SM, Rivera DR et al (2020) Clinical impact of COVID-19 on patients with cancer (CCC19): a cohort study. Lancet. 395(10241):19071918

14. Dai M, Liu D, Liu M, Zhou F, Li G, Chen Z, Zhang Z, You H, Wu $\mathrm{M}$, Zheng $\mathrm{Q}$, Xiong $\mathrm{Y}$, Xiong $\mathrm{H}$, Wang $\mathrm{C}$, Chen $\mathrm{C}$, Xiong $\mathrm{F}$, Zhang Y, Peng Y, Ge S, Zhen B, Yu T, Wang L, Wang H, Liu Y, Chen Y, Mei J, Gao X, Li Z, Gan L, He C, Li Z, Shi Y, Qi Y, Yang J, Tenen DG, Chai L, Mucci LA, SantillanaM, Cai H (2020) Patients with cancer appear more vulnerable to SARS-CoV-2: a multicenter study during the COVID-19 outbreak. https://doi.org/10.1158/ 2159-8290.CD-20-0422

15. Zhang L, Zhu F, Xie L, Wang C, Wang J, Chen R, Jia P, Guan HQ, Peng L, Chen Y, Peng P, Zhang P, Chu Q, Shen Q, Wang Y, Xu SY, Zhao JP, Zhou M (2020) Clinical characteristics of COVID-19infected cancer patients: a retrospective case study in three hospitals within Wuhan, China. Ann Oncol 31(7):894-901

16. He W, Chen L, Chen L, Yuan G, Fang Y, Chen W, Wu D, Liang B, Lu X, Ma Y, Li L, Wang H, Chen Z, Li Q, Gale RP (2020) COVID19 in persons with haematological cancers. Leukemia. 34(6):16371645

17. Yang K, Sheng Y, Huang C, Jin Y, Xiong N, Jiang K, Lu H, Liu J, Yang J, Dong Y, Pan D, Shu C, Li J, Wei J, Huang Y, Peng L, Wu M, Zhang R, Wu B, Li Y, Cai L, Li G, Zhang T, Wu G (2020) Clinical characteristics, outcomes, and risk factors for mortality in patients with cancer and COVID-19 in Hubei, China: a multicentre, retrospective, cohort study. Lancet Oncol 21(7):904-913

18. Stuck AE, Minder CE, Frey FJ (1989) Risk of infectious complications in patients taking glucocorticosteroids. Rev Infect Dis 11(6):954-963

19. Guzik TJ, Mohiddin SA, Dimarco A, Patel V, Savvatis K, MarelliBerg FM, Madhur MS, Tomaszewski M, Maffia P, D'Acquisto F, Nicklin SA, Marian AJ, Nosalski R, Murray EC, Guzik B, Berry C, Touyz RM, Kreutz R, Wang DW, Bhella D, Sagliocco O, Crea F, Thomson EC, McInnes IB (2020) COVID-19 and the cardiovascular system: implications for risk assessment, diagnosis, and treatment options. Cardiovasc Res 116(10):1666-1687. https://doi.org/ $10.1093 /$ cvr/cvaa106

20. Bersanelli M (2020) Controversies about COVID-19 and anticancer treatment with immune checkpoint inhibitors. Immunotherapy. 12(5):269-273

21. Stathopoulos K et al (2020) Retrospective analysis of chest CT imaging findings of COVID-19 in cancer patients: initial experience in a tertiary cancer center. Clin Radiol Imaging J 4(3):000176

Publisher's note Springer Nature remains neutral with regard to jurisdictional claims in published maps and institutional affiliations. 